ARTICLE

\title{
Salicylic acid biosynthesis is enhanced and contributes to increased biotrophic pathogen resistance in Arabidopsis hybrids
}

Li Yang ${ }^{1,2, \star}$, Bosheng $\mathrm{Li}^{1,2, \star}$, Xiao-yu Zheng ${ }^{3}$, Jigang $\mathrm{Li}^{4}$, Mei Yang ${ }^{1}$, Xinnian Dong ${ }^{3}$, Guangming $\mathrm{He}^{1}$, Chengcai $A n^{1} \&$ Xing Wang Deng ${ }^{1,2}$

Heterosis, the phenotypic superiority of a hybrid over its parents, has been demonstrated for many traits in Arabidopsis thaliana, but its effect on defence remains largely unexplored. Here, we show that hybrids between some $A$. thaliana accessions show increased resistance to the biotrophic bacterial pathogen Pseudomonas syringae pv. tomato (Pst) DC3000. Comparisons of transcriptomes between these hybrids and their parents after inoculation reveal that several key salicylic acid (SA) biosynthesis genes are significantly upregulated in hybrids. Moreover, SA levels are higher in hybrids than in either parent. Increased resistance to Pst DC3000 is significantly compromised in hybrids of pad4 mutants in which the SA biosynthesis pathway is blocked. Finally, increased histone $\mathrm{H} 3$ acetylation of key SA biosynthesis genes correlates with their upregulation in infected hybrids. Our data demonstrate that enhanced activation of SA biosynthesis in A. thaliana hybrids may contribute to their increased resistance to a biotrophic bacterial pathogen.

\footnotetext{
${ }^{1}$ Peking-Yale Joint Center for Plant Molecular Genetics and Agro-Biotechnology, State Key Laboratory of Protein and Plant Gene Research, The PekingTsinghua Center for Life Sciences, School of Advanced Agricultural Sciences and School of Life Sciences, Peking University, Beijing 100871, China.

${ }^{2}$ Department of Molecular, Cellular and Developmental Biology, Yale University, New Haven, Connecticut 06520, USA. ${ }^{3}$ Howard Hughes Medical InstituteGordon and Betty Moore Foundation, Department of Biology, Duke University, Durham, North Carolina 27708, USA. ${ }^{4}$ State Key Laboratory of Plant Physiology and Biochemistry, College of Biological Sciences, China Agricultural University, Beijing 100193, China. * These authors contributed equally to this work. Correspondence and requests for materials should be addressed to G.H. (email: heguangming@pku.edu.cn) or to C.A. (email: chcaian@pku.edu.cn) or to X.W.D (email: deng@pku.edu.cn).
} 
$\mathrm{H}$ ybrid vigour, or heterosis, refers to the phenotypic superiority of a hybrid over its parents and has been demonstrated for many traits, such as growth rate, biomass and stress tolerance. Although heterosis has been exploited extensively in crop production for many years, our understanding of its molecular basis is still rudimentary ${ }^{1-5}$. Classical theories, including dominance, overdominance and epistasis, have been proposed to explain heterosis from a quantitative genetics perspective $\mathrm{e}^{5-7}$. These theories have not elucidated the molecular basis of heterosis ${ }^{6}$. Recently, several studies have shed light on potential molecular mechanisms of heterosis in plants. For example, changes in the expression of circadian regulatory genes contribute to biomass heterosis in Arabidopsis thaliana by altering circadian rhythms in hybrids 8 . Another study reported the first single overdominant gene, SINGLE FLOWER TRUSS, responsible for fruit yield heterosis in tomato 9 . In addition, several studies that surveyed the transcriptomes and epigenomes (including DNA methylomes, small RNAomes and genome-wide distribution of histone modifications) of hybrids and their parental lines in various plant species $1,2,5,10,11$ suggesting that both transcriptional and epigenetic variations may play a role in the molecular mechanisms of heterosis.

Natural accessions of $A$. thaliana are largely homozygous due to their selfing property ${ }^{12}$. Hybrids resulting from crosses of two distinct accessions may exhibit heterosis, as demonstrated in A. thaliana for biomass ${ }^{13,14}$, photosynthetic efficiency ${ }^{15}$, seedling viability ${ }^{16}$, seed number ${ }^{17}$, phosphate uptake ${ }^{18}$ and freezing tolerance $^{19,20}$. Two previous studies ${ }^{21,22}$ suggested that the inappropriate activation of immune responses in $\mathrm{F}_{1}$ hybrids, caused by allelic interactions of NB-LRR immune receptor genes or accelerated cell death genes, was the molecular basis of hybrid necrosis. These studies provided a molecular explanation for hybrid necrosis in which the hybrids exhibited growth defects, but not for the heterotic defence responses in which the hybrids showed normal growth.

Natural variations in the ability of plants to defend against infection are expected because of the significant selective pressure imposed by the pathogens. Plants can be attacked by diverse groups of pathogens, including bacteria, fungi, oomycetes, viruses and nematodes ${ }^{23}$. On recognition of the attacking pathogens, plants can produce immune signals and activate batteries of defence responses ${ }^{24,25}$. Salicylic acid (SA) is an immune signal that increases in response to pathogen infection ${ }^{26}$, and this increase often coincides with elevated expression of antimicrobial pathogenesis-related (PR) genes and enhanced disease resistance ${ }^{27,28}$. However, mutants or transgenic plants impaired in SA accumulation are unable to trigger efficient defence responses and are hypersusceptible to infection ${ }^{29}$. Moreover, exogenous applications of SA can induce plant resistance to various pathogens ${ }^{30}$.

Two SA biosynthetic pathways exist in plants: one from cinnamate that is catalysed by phenylalanine ammonia lyase, and the other from chorismate that is catalysed by isochorismate synthase (ICS) ${ }^{28,31}$. The A. thaliana genome contains two ICS genes, ICS1 (also known as SID2) and ICS2 $2^{31}$. The function of ICS1 is predominant, because the total SA level in the ics 1 single mutant after infection is only $5-10 \%$ of that in the infected wild type $^{32}$. Other A. thaliana mutants that are deficient in SA biosynthesis include eds5, eds1, pad4 and the double mutant cbp60g sard1 (refs 31,33-39). EDS5 (also known as SID1) encodes a predicted protein homologous to the multidrug and toxin extrusion family of transporter proteins and is required for exporting SA out of the chloroplasts where it is synthesized ${ }^{35-37}$. In $e d s 1$ and pad4 mutants, the pathogen-activated expression of ICS1 and EDS5 is blocked, suggesting that EDS1 and PAD4 function upstream of ICS1 and EDS5 $5^{33,38,39}$. CBP60g and SARD1 are transcription factors that bind to the promoter of ICS1 and activate its expression. Accordingly, the cbp60g sard1 double mutant is partially deficient in pathogen-induced SA biosynthesis ${ }^{40}$.

In this study, we show that certain A. thaliana crosses have an increased resistance to the biotrophic bacterial pathogen Pseudomonas syringae pv. tomato (Pst) DC3000. We found that the expression levels of several key SA biosynthesis genes were significantly upregulated in hybrids, which ultimately led to higher levels of SA, in both its active free form (SA) and its storage form (SA glucoside, or SAG). Moreover, we show that the increased pathogen resistance in the $\mathrm{F}_{1}$ hybrids was compromised when the production of SA was blocked by mutations in $P A D 4$. Finally, we discovered that epigenetic modifications were associated with the increased expression of SA biosynthesis genes in hybrids, further supporting our hypothesis that enhanced activation of the SA biosynthesis pathway in hybrids contributes to their increased resistance to this biotrophic bacterial pathogen.

\section{Results}

Heterosis for biotrophic bacterial defence in Arabidopsis. To investigate whether increased resistance to biotrophic bacterial pathogens exists in certain $A$. thaliana hybrids, we crossed 20 accessions (Supplementary Table 1) reciprocally with Arabidopsis ecotype Columbia-0 (Col-0) and evaluated the resulting hybrids and their parents for resistance to the pathogenic bacterium Pst DC3000. We investigated leaf phenotypes 1-5 days after pathogen infiltration, and found that the differences between parents and hybrids were most significant at 5 days post infiltration (dpi). Figure 1 shows the leaves of hybrids and their parents from two representative crosses at 5 days after infiltration with Pst DC3000 at $1 \times 10^{5}$ colony-forming units (c.f.u.) per ml. We found obvious chlorotic symptoms on the leaves of the three parental accessions (Col-0, Sei-0 and Aa-0) and on the two $F_{1}$ hybrids Aa- $0 \times$ Col- 0 (represented by Fac) and Col- $0 \times \mathrm{Aa}-0$ (represented by $\mathrm{Fca}$ ) in which $\mathrm{Aa}-0$ or $\mathrm{Col}-0$ was the maternal line, respectively (Fig. 1b). In contrast, chlorotic symptoms were rarely observed on the leaves of the two $F_{1}$ hybrids from the cross between Sei- 0 and Col- 0 (Sei- $0 \times$ Col- 0 and Col- $0 \times$ Sei- 0 , represented by Fsc and Fcs, respectively; Fig. 1b).

To further confirm the increased resistance in Fsc and Fcs hybrids, we measured the bacterial titer in leaves at 0 and 5 dpi. As shown in Fig. 1c, while there were no significant differences between parents and hybrids in the initial inoculation amount ( $0 \mathrm{dpi}$ ), the bacterial titer was $\sim 10$-fold lower in hybrids than in their parents at $5 \mathrm{dpi}(P<0.01$, Student's $t$-test $)$, indicating that pathogenic bacterial growth was greatly inhibited in the Fsc and Fcs $F_{1}$ populations. No significant differences in the growth of the pathogenic bacteria were observed between the Fac and Fca hybrids and their parents (Fig. 1c).

Among 20 accessions tested, we found significant heterosis for defence against Pst DC3000 (that is, The hybrids were superior to both parents, meaning that pathogenic bacterial growth was significantly inhibited in the $\mathrm{F}_{1}$ populations compared with that in either parent $(P<0.01$, Student's $t$-test $)$ in hybrids resulting from crosses between Col- 0 and the two accessions Sei- 0 and Ler. No evident heterosis for biotrophic bacterial defence was observed in hybrids resulting from crosses between Col-0 and the other 18 accessions (Supplementary Fig. 1 and Supplementary Table 1). Notably, there were no significant differences in resistance between reciprocal crosses from the same parental pairs, suggesting that there are no obvious maternal effects on heterosis for biotrophic bacterial defence. 


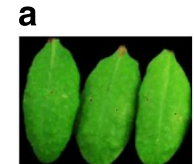

Col-0

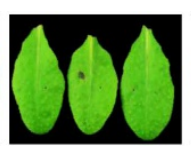

Sei-0

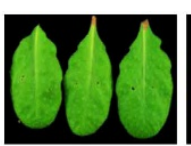

Fsc

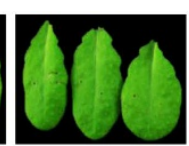

Fcs

$\operatorname{Mock}(10 \mathrm{mM} \mathrm{MgCl}$ )

b

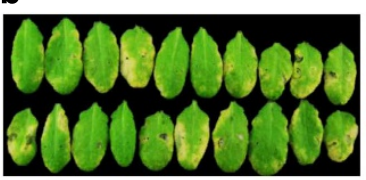

Col-0

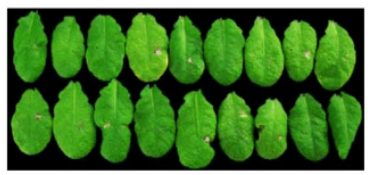

Fsc

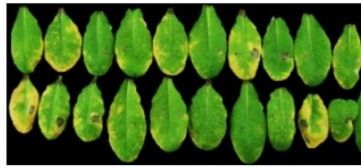

Sei-0

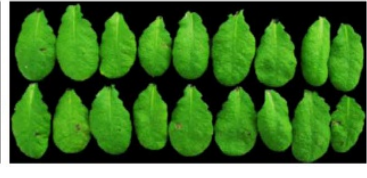

Fcs

Pst DC3000

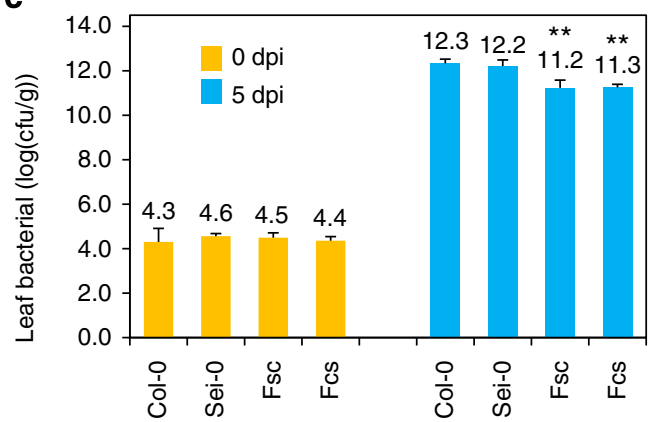

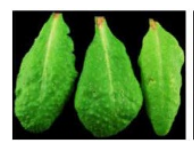

Col-0

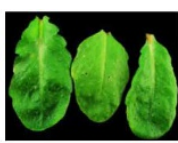

Aa-0

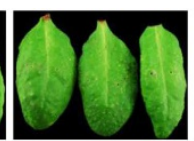

Fac

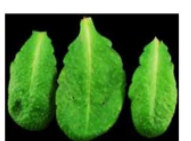

Fca

Mock (10 mM MgCl 2 )

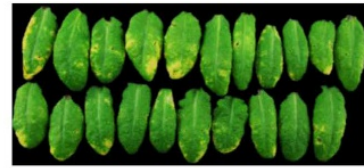

Col-0

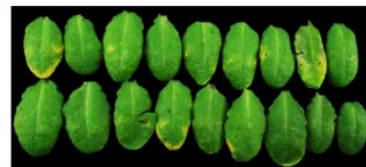

Fac

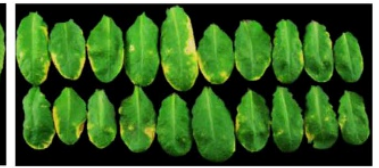

Aa-0

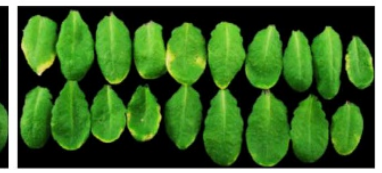

Fca

Pst DC3000

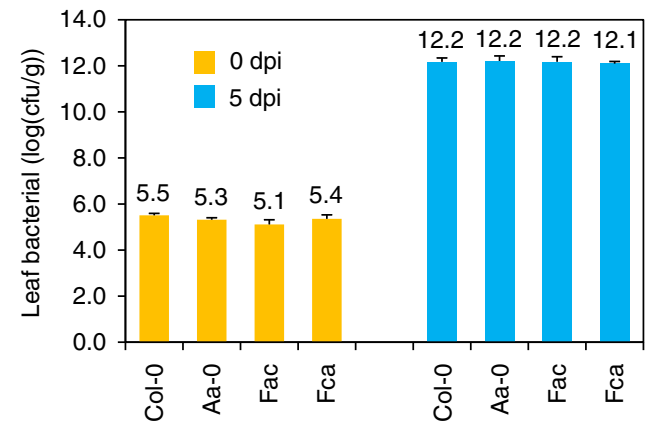

Figure 1 | Bacterial defence phenotypes of Arabidopsis thaliana $\mathbf{F}_{\mathbf{1}}$ hybrids and their parents. (a) Phenotypes of $\mathrm{F}_{1}$ hybrids and their parents 5 dpi with

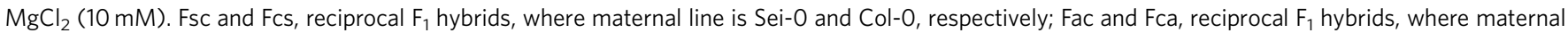
line is Aa-O and Col-0, respectively. (b) Phenotypes of $\mathrm{F}_{1}$ hybrids and their parents 5 dpi with Pseudomonas syringae pv. tomato (Pst) DC3000 ( $1 \times 10^{5}$

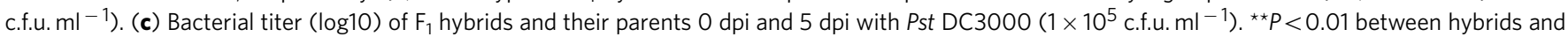
parents (Student's $t$-test). Bacterial growth is expressed as mean values of viable bacteria per gram of leaf tissue \pm s.d.. Error bars indicate s.d.. Data are shown as mean $\pm \mathrm{s}$.d. ( $n=8, \mathrm{n}$ means biological replication).

A series of studies ${ }^{21,22,41,42}$ reported that some intraspecific hybrids in $A$. thaliana expressed necrosis when grown at $16^{\circ} \mathrm{C}$, but these necrotic phenotypes largely disappeared at $23^{\circ} \mathrm{C}$. This phenomenon was considered to represent negative heterosis for biomass (or hybrid necrosis), as the hybrids showed inferior growth at $16^{\circ} \mathrm{C}$ compared with their parents. However, it could also be regarded as a case of positive heterosis for defence, because the hybrids showed an increased resistance to the pathogen Hyaloperonospora parasitica 22,42 , mediated by increased SA levels $^{42}$ and elevated PR1 expression ${ }^{21}$. Two studies ${ }^{21,22}$, which used QTL mapping and whole-genome transcriptome analyses, showed that hybrid necrosis results from inappropriate activation of the immune system, caused by an interallelic interaction of an NB-LRR immune receptor gene or the accelerated cell death gene ACD6. Accordingly, we wondered whether the increased resistance observed in $\mathrm{F}_{1}$ hybrids of Col- $0 \times$ Sei- 0 and Col- $0 \times$ Ler represented cases of hybrid necrosis.

We examined the viability and fertility of $F_{1}$ hybrids from four combinations, Col- $0 \times$ Sei- 0 and Col- $0 \times$ Ler, which showed heterosis for biotrophic bacterial defence, and Col- $0 \times$ Ws and Col- $0 \times$ Aa- 0 , which did not. All $\mathrm{F}_{1}$ hybrids were morphologically normal and vigourous at $16^{\circ} \mathrm{C}$ (Supplementary Fig. 2a,b), and showed no more cell necrosis than their parents based on trypan blue staining in leaves (Supplementary Fig. 2c). Moreover, compared with their parents, the hybrids exhibiting heterosis for biotrophic bacterial defence (Fsc, Fcs, Flc and Fcl) did not show more highly activated SA pathway genes (PAD4, EDS1, SARD1, CBP60g, ICS1 and PR1; Supplementary Fig. 2d). This result was opposite to that found in necrotic hybrids that expressed obvious growth defects and aberrant activation of these genes when grown at $16^{\circ} \mathrm{C}$ without pathogen infection. These results suggest that the heterosis we have demonstrated for biotrophic bacterial defence results from a molecular mechanism different from hybrid necrosis.

SA biosynthesis genes are upregulated in hybrids. To identify genes potentially associated with heterosis for biotrophic bacterial defence, we used mRNA-sequencing (mRNA-seq) to explore the transcriptomes of two A. thaliana accessions, Col-0 and Sei-0, and their reciprocal hybrids, Fsc and Fcs, which showed heterosis for Pst DC3000 defence. The leaves of 4-week-old hybrid and parental plants grown in short-day conditions were infiltrated with Pst DC3000, and 30 leaves were collected from different 
plants at 1, 2 and 3 dpi. Then, mRNA-seq libraries were constructed and subjected to high-throughput Illumina sequencing. Three independent biological replicates were generated for each sample (Supplementary Table 2). All sequencing reads were aligned to the $A$. thaliana reference genome (Col-0, TAIR10), and a total of $\sim 900$ million genome-matched reads were obtained for 36 libraries (Supplementary Table 3).

At each time point after inoculation, we identified differentially expressed genes (DEGs) between parents and hybrids (Supplementary Figs 3, 4 and 5). We identified between 2,506 and 5,577 DEGs that showed non-additive actions in reciprocal hybrids. The non-additive group was subdivided into four distinct modes: above-high parent, high parent, low parent and below-low parent (Supplementary Fig. 3c,d). A total of 3,194 DEGs that showed above-high parent or below-low parent expression in both hybrids (Fig. 2a; Supplementary Data 1) were chosen for further analysis. These 3,194 genes were further classified into four groups based on expression changes across the three time points: expression continuously increased; expression continuously decreased; expression increased and then decreased; and expression decreased and then increased. On the basis of these criteria, 1,827 genes showing the same expression patterns between reciprocal hybrids were selected for Gene Ontology (GO) analysis (Fig. 2b; Supplementary Data 1). The most significantly enriched GO term was 'response to stimulus' $\left(P<5.00 e^{-7}\right.$, Hypergeometric test; Fig. 2c). A set of 80 genes termed 'response to bacterium' (Fig. 2d; Supplementary Data 1) seemed the most relevant to the goal of this study and was studied further. We compared the expression levels of these 80 genes between hybrids and parents, and found that the genes with the most significant change in expression between parents and hybrids were enriched in the SA pathway. These included CBP60g and $S A R D 1$, which encode the transcriptional activators of ICS1, and $P R 1$, the most commonly used marker gene for SA signalling (Fig. 2d).

SA is a well-known hormone important for plant defence ${ }^{28,29}$. That genes involved in the SA pathway changed significantly in hybrids relative to their parents suggests that enhanced activation of the SA pathway may be related to the increased resistance to Pst DC3000 in A. thaliana hybrids. To test this hypothesis, we extended our expression analysis by performing detailed timecourse experiments. Leaf samples of hybrids and parents were collected every $8 \mathrm{~h}$ after infiltration up to $48 \mathrm{~h}$ and subjected to real-time quantitative reverse transcription PCR (qRT-PCR). As shown in Figs 3 and 5 and Supplementary Fig. 6, expression of PR1, PAD4, EDS1, SARD1 and CBP60g was significantly upregulated in the $\mathrm{F}_{1}$ hybrids of Col- $0 \times$ Sei- 0 compared with their parents, and expression of these genes peaked in the hybrids $8 \mathrm{~h}$ earlier than in their parents. No expression changes were observed for these genes in the $\mathrm{F}_{1}$ hybrids of Col- $0 \times \mathrm{Aa}-0$ (Fig. 3b; Supplementary Fig. 7), which is consistent with the lack of evident heterosis for Pst DC3000 defence in these hybrids (Fig. 1). These results imply that the upregulation of key genes in the $\mathrm{SA}$ biosynthesis pathway in $\mathrm{F}_{1}$ hybrids may play a role in the increased resistance of hybrids to biotrophic bacterial pathogen. a

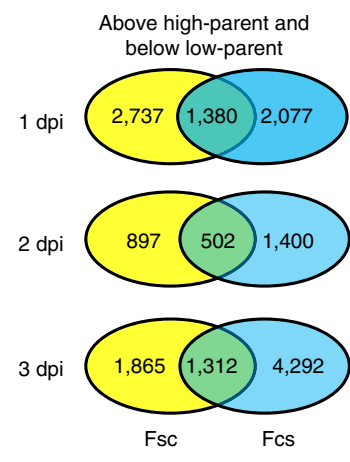

b
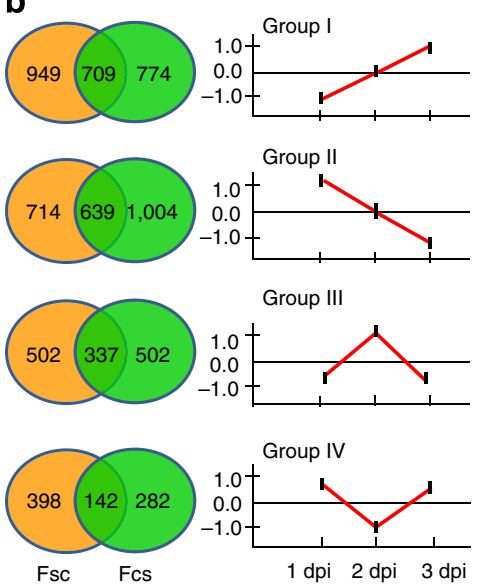

C

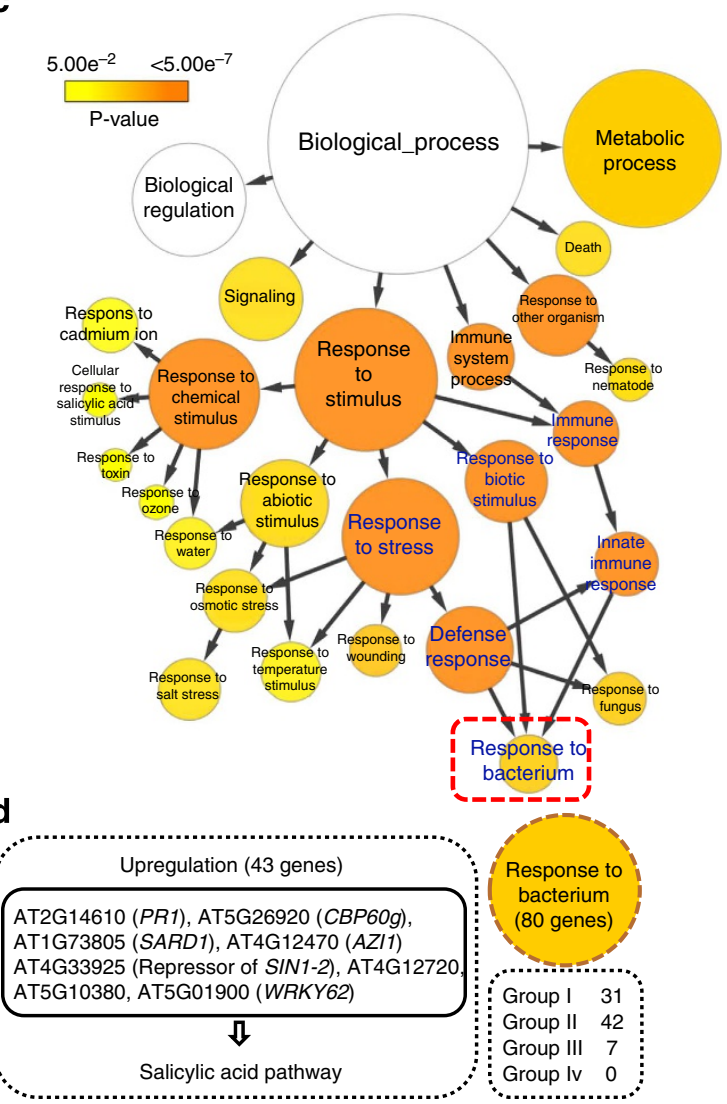

Figure 2 | DEGs involved in bacterial defence selected by cluster and functional classification analyses. (a) Venn diagram showing the number of 'above-high parent' and 'below-low parent' genes in each Arabidopsis thaliana hybrid at three time points. (b) Venn diagram showing the number of genes (selected from (a)) in each Cluster Analysis Group in $\mathrm{F}_{1}$ hybrids. Group I: expression continuously increased; group II: expression continuously decreased; group III: expression increased first and then decreased; and group IV: expression decreased first and then increased. (c) Enrichment of selected GO categories for genes selected from (b). The biological process with false discovery rate (adjusted $P<0.05$, Student's $t$-test) is shown. (d) Some genes in the salicylic acid pathway, categorized as 'response to bacterium' by $G O$ analysis, were upregulated in $F_{1}$ hybrids. 

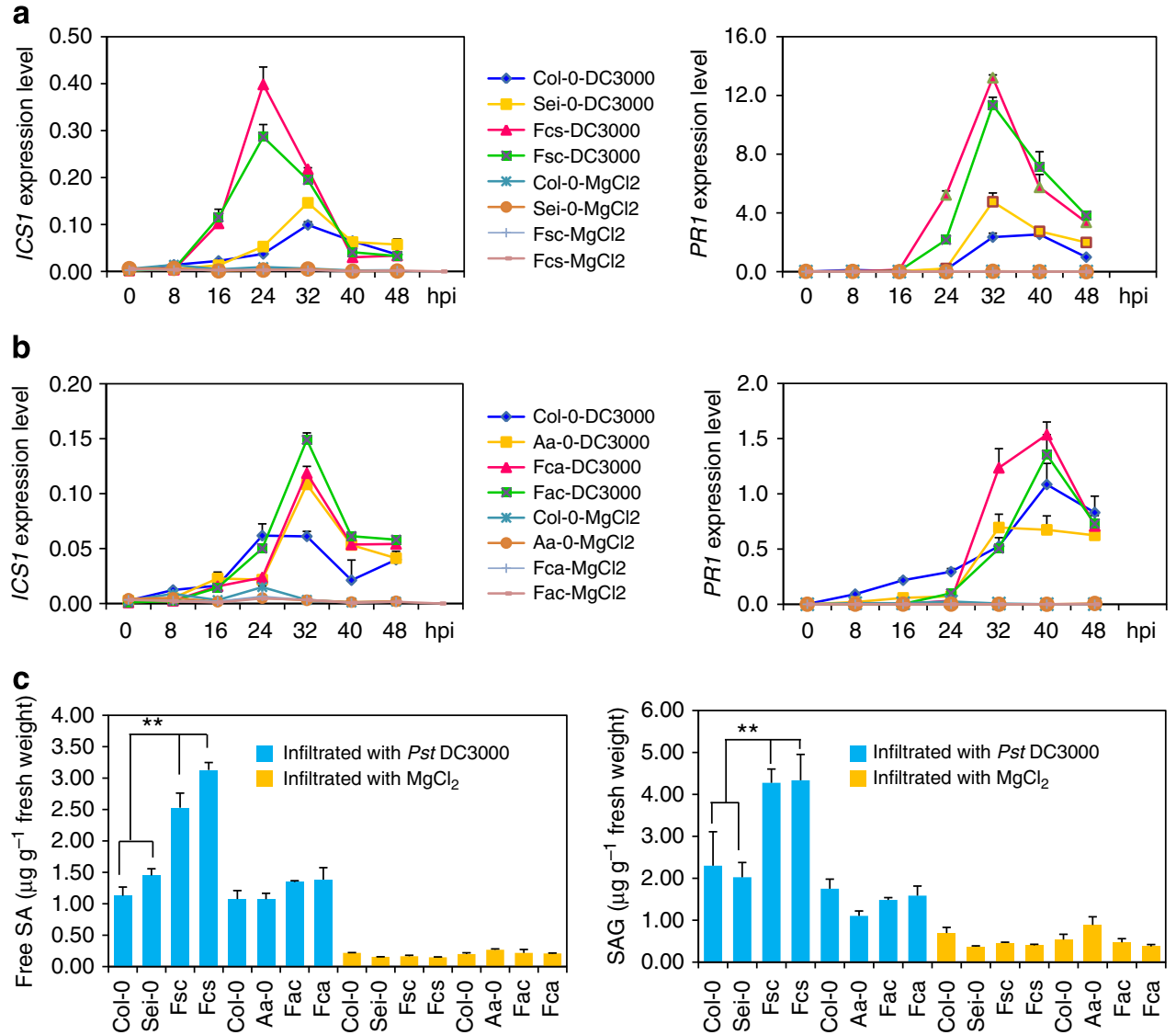

Figure 3 | Free SA and SA glycoside levels in Arabidopsis thaliana $\mathbf{F}_{\mathbf{1}}$ hybrids and their parents. (a) qPCR analyses of ICS1 and $P R 1$ expression in $\mathrm{F}_{1}$ hybrids and parents of Col-0 $\times$ Sei-0 every $8 \mathrm{~h}$ post infiltration (hpi) up to $48 \mathrm{hpi}$ with Pseudomonas syringae pv. tomato (Pst) DC3000 at $1 \times 10^{5}$ c.f.u. $\mathrm{ml}^{-1}$ and $\mathrm{MgCl}_{2}$. Fsc and Fcs, reciprocal $\mathrm{F}_{1}$ hybrids, where maternal line is Sei-0 and Col-0, respectively. (b) qPCR analyses of ICS1 and PR1 expression in $\mathrm{F}_{1}$ hybrids and parents of Col- $0 \times$ Aa- 01 every $8 \mathrm{~h}$ post infiltration (hpi) up to 48 hpi with Pst $\mathrm{DC} 3000$ at $1 \times 10^{5}$ c.f.u. $\mathrm{ml}^{-1}$. Fac and Fca, reciprocal $\mathrm{F}_{1}$ hybrids, where maternal line is $\mathrm{Aa}-\mathrm{O}$ and Col-0, respectively. Data are standardised for abundance of Actin transcript. (c) Free SA and SAG levels in $\mathrm{F}_{1}$ hybrids and parents of two crosses 1 dpi with Pst DC3000 at $1 \times 10^{5}$ c.f.u. $\mathrm{ml}^{-1}$. The results are a representative of three biological repetitions. Error bars indicate s.d.. Data are shown as mean \pm s.d. $\left(n=3, n\right.$ means technical replication). ${ }^{\star \star} P<0.01$ between hybrids and parents (Student's $t$-test).

More SA accumulates in hybrids after Pst DC3000 inoculation. In $A$. thaliana, pathogen-induced biosynthesis of SA starts from chorismate is catalysed by ICS $1^{31,32}$. On the basis of our mRNAseq data, the expression of ICS1 at 1 dpi was 10 -fold higher in $\mathrm{F}_{1}$ hybrids than in parents, suggesting that $\mathrm{SA}$ biosynthesis is more active in $\mathrm{F}_{1}$ hybrids than in their parents after pathogen infection. To further test this idea, we analysed expression of ICS1 in $\mathrm{F}_{1}$ hybrids of Col- $0 \times$ Sei- 0 and Col- $0 \times$ Aa- 0 relative to their respective parents after infiltration with Pst DC3000 or $10 \mathrm{mM}$ $\mathrm{MgCl}_{2}$ (control). As shown in Fig. 3a,b, the expression level of ICS1 showed a greater and more rapid increase in the reciprocal $\mathrm{F}_{1}$ hybrids of Col- $0 \times$ Sei- 0 , but not in the $\mathrm{F}_{1}$ hybrids of Col- $0 \times$ Aa- 0 , compared with their respective parents.

Next, we determined the SA levels in $\mathrm{F}_{1}$ hybrids and their parents after infiltration with Pst DC3000. As shown in Fig. 3c, at $1 \mathrm{dpi}$, more SA (including free SA and SAG) had accumulated in the $F_{1}$ hybrids Fsc and FCs than in their parents $(P<0.01$, Student's $t$-test). No significant changes in SA accumulation were observed in the $\mathrm{F}_{1}$ hybrids $\mathrm{Fac}$ and $\mathrm{Fca}$ relative to their parents. Altogether, our data indicate that increased SA accumulation may be responsible for increased resistance to biotrophic bacterial pathogens in the $F_{1}$ hybrids Fcs and Fsc.

An important defence response induced by SA is the triggering of PR gene expression, especially $P R 1^{43}$. An examination of $P R 1$ expression showed that $P R 1$ was significantly upregulated in the reciprocal $F_{1}$ hybrids $F s c$ and $F c s$ relative to their parents, whereas no obvious changes in PR1 expression were found in the reciprocal $F_{1}$ hybrids $F a c$ and $F c a$ relative to their parents (Fig. 3a,b). These results indicate that increased SA accumulation, possibly due to enhanced activation of the SA biosynthesis pathway, may be involved in increased resistance to biotrophic bacterial pathogens in A. thaliana hybrids.

Blocking SA biosynthesis compromises heterosis in hybrids. To substantiate the role of SA in heterosis for biotrophic bacterial defence, we asked whether blocking the SA biosynthesis pathway could compromise the heterotic phenotypes of $\mathrm{F}_{1}$ hybrids. For this purpose, we chose PAD4 to examine as a key gene in the SA biosynthesis pathway ${ }^{44}$ that is mutated in more than one A. thaliana ecotype. PAD4 is a lipase-like protein that functions upstream of the SA biosynthesis pathway to control defence responses in $A$. thaliana ${ }^{33}$. Compared with wild type, pad4 mutants display enhanced susceptibility to two virulent $P$. syringae pathogens (Pst $\mathrm{DC} 3000^{43}$ and $P$. syringae pv. maculicola ES4326 $6^{45,46}$ ), resulting from the reduced synthesis and accumulation of $\mathrm{SA}$ and $\mathrm{SAG}^{33,38}$. A pad4 mutant line in the Ler background (pad4-2) ${ }^{44}$ and a T-DNA insertion line in the Col-0 background (SALK_089936) were used to generate reciprocal $\mathrm{F}_{1}$ hybrid lines. We first confirmed that 


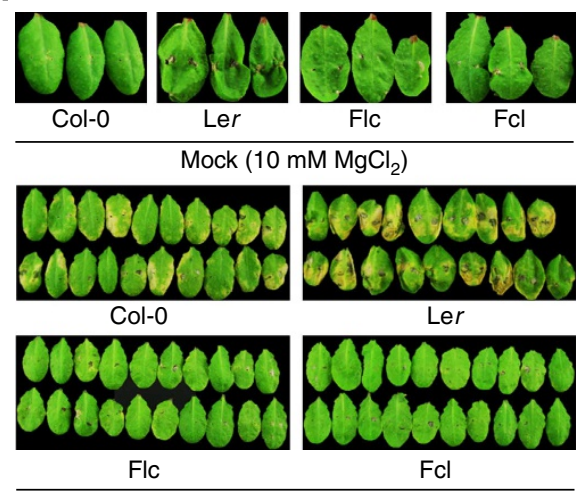

Pst DC3000

b
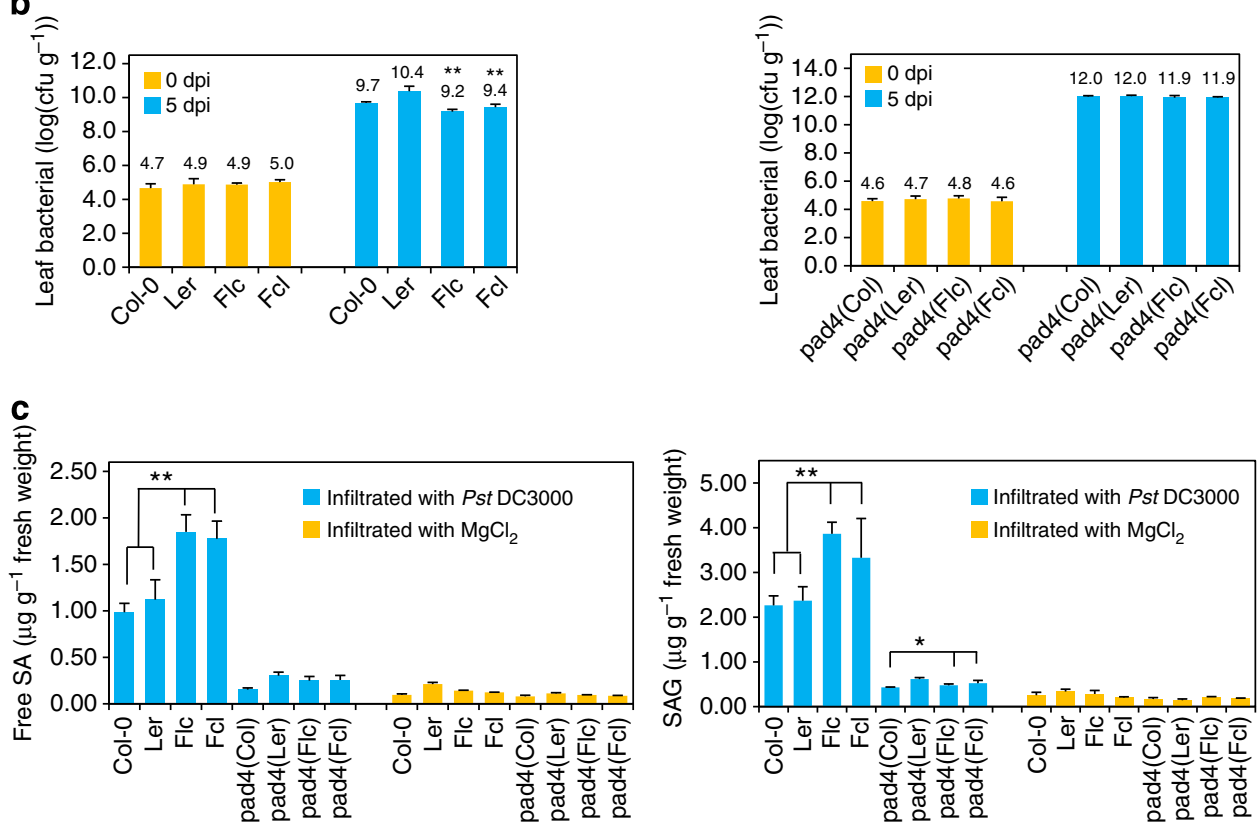

Figure 4 | Increased resistance to the biotrophic bacterial pathogen was compromised in $\mathbf{F}_{\mathbf{1}}$ hybrids of pad4 mutants. (a) Phenotypes of Col- $0 \times$ Ler and pad4 $(\mathrm{Col}) \times$ pad4 (Ler) parental lines and their respective $\mathrm{F}_{1}$ hybrids 5 dpi with $\mathrm{MgCl}_{2}(10 \mathrm{mM})$ or Pseudomonas syringae pv. tomato $(P s t)$ DC $3000\left(1 \times 10^{5}\right.$ c.f.u. $\mathrm{ml}^{-1}$ ). Flc and $\mathrm{Fcl}$, reciprocal $\mathrm{F}_{1}$ hybrids, where maternal line is Ler and Col-0, respectively. (b) Bacterial titer (log10) of Col-0 $\times$ Ler and pad4 $(\mathrm{Col}) \times$ pad4 (Ler) parental lines and their respective $\mathrm{F}_{1}$ hybrids $5 \mathrm{dpi}$ with Pst DC3000 $\left(1 \times 10^{5}\right.$ c.f.u. $\left.\mathrm{ml}^{-1}\right)$. Bacterial growth is expressed as mean values of viable bacteria per gram of leaf tissue \pm s.d. Error bars indicate s.d.. Data are shown as mean \pm s.d. $(n=8, n$ means biological replication). (c) Free $S A$ and SA glycoside (SAG) levels in Col-0 $\times$ Ler and pad4 (Col) $\times$ pad4 (Ler) parental lines and their respective $\mathrm{F}_{1}$ hybrids 1 dpi with Pst DC3000 at $1 \times 10^{5}$ c.f.u. $\mathrm{ml}^{-1}$. The results are a representative of three biological repetitions. Error bars indicate s.d.. Data are shown as mean $\pm \mathrm{s}$.d. $(n=3, n$ means technical replication). ${ }^{\star} P<0.05$ and ${ }^{\star \star} P<0.01$ between hybrids and parents (Student's $t$-test).

expression of PAD4 was downregulated in the two pad4 parental lines (Supplementary Fig. 8). In the absence of a pad4 mutation, the $\mathrm{F}_{1}$ hybrids of Col-0 and $\mathrm{Ler}$ ( $\mathrm{Flc}$ and $\mathrm{Fcl}$ ) had significantly increased resistance to biotrophic bacterial invasion $(P<0.01$, Student's $t$-test; Fig. 4a,b), and significant greater accumulation of both free SA and SAG $(P<0.01$, Student's $t$-test; Fig. $4 \mathrm{c})$ relative to their parents. For pad4 mutants, both the parental lines (pad4 $(\mathrm{Col})$ and pad4 (Ler)) and their reciprocal $\mathrm{F}_{1}$ hybrids (pad4 (Flc) and pad4 $(\mathrm{Fcl}))$ showed greater susceptibility to Pst DC3000 than their wild-type counterparts (Fig. 4a,b). Moreover, the heterosis for biotrophic bacterial defence in both reciprocal $F_{1}$ hybrids was greatly compromised, and no significant differences in symptoms or bacterial titers were observed among the hybrids and parents (Fig. 4a,b). In addition, there were no significant differences in SA accumulation in the $F_{1}$ hybrids compared with their parents (Fig. 4c). Notably, SA levels were reduced to control levels (treated with $10 \mathrm{mM} \mathrm{MgCl}_{2}$ ) in both parents and hybrids
(Fig. 4c). We then tested the expression profiles of ICS1 and PR1, which act downstream of PAD4 in the SA biosynthesis pathway. At $1 \mathrm{dpi}$, both genes were upregulated in $\mathrm{F}_{1}$ hybrids Flc and $\mathrm{Fcl}$, but not in $\mathrm{F}_{1}$ hybrids pad4 (Flc) and pad4 (Fcl) (Supplementary Fig. 9). These data further indicate that the increased level of SA resulting from enhanced activation of the SA biosynthesis pathway in hybrids plays an essential role in heterosis for biotrophic bacterial defence.

H3Ac of SA biosynthesis genes increased in hybrids. Several reports recently showed that chromatin modifications may play important roles in hybrid vigour ${ }^{10,47}$. Chromatin modifications have also been suggested to play a role in plant defence responses by regulating gene expression ${ }^{48,49}$. We thus asked whether chromatin modifications might be involved in heterosis for biotrophic bacterial defence in Arabidopsis. We examined the 
a
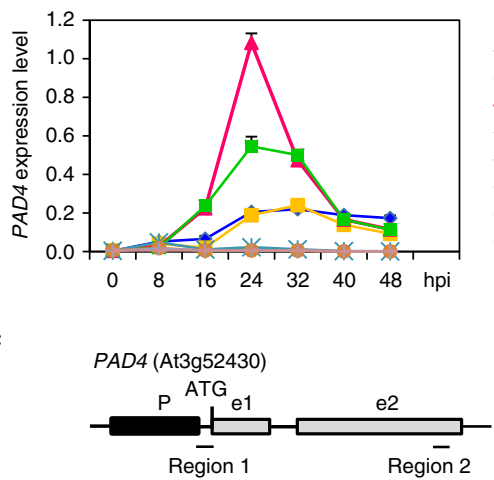

d

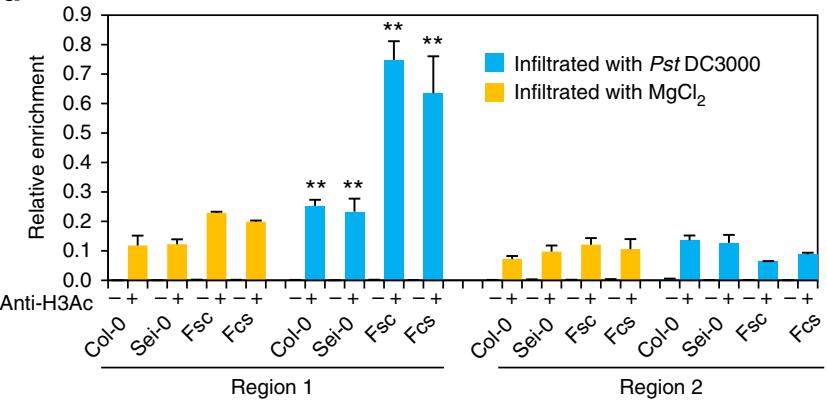

e

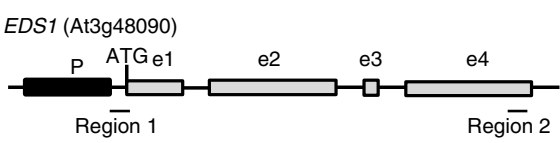

$\mathbf{f}$

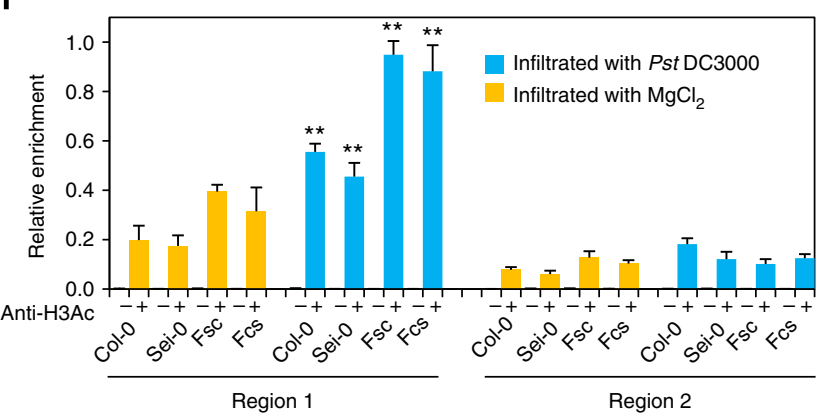

b

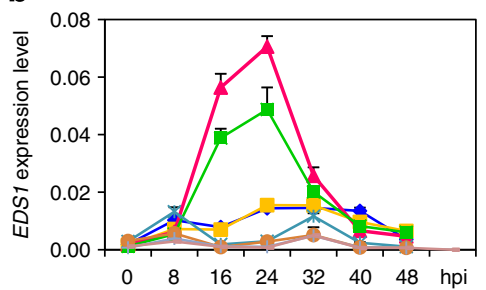

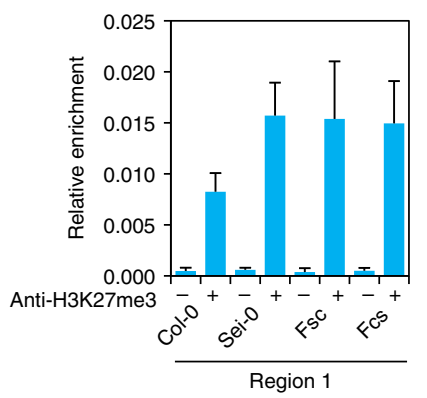

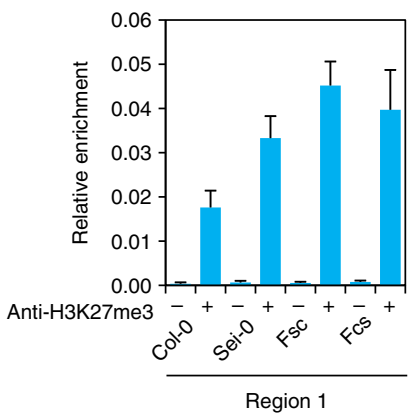

Figure 5 | Increased $\mathbf{H 3}$ acetylation correlates with altered expression of PAD4 and EDS1 in $\mathbf{F}_{\mathbf{1}}$ hybrids. (a,b) qPCR analyses of PAD4 and EDS1 expression in $\mathrm{F}_{1}$ hybrids and parents of $\mathrm{Col}-0 \times$ Sei- 0 every $8 \mathrm{~h}$ post infiltration (hpi) up to $48 \mathrm{hpi}$ with Pseudomonas syringae pv. tomato (Pst) DC3000 at $1 \times 10^{5}$ c.f.u. $\mathrm{ml}^{-1}$ or $\mathrm{MgCl}_{2}$. Fsc and Fcs, reciprocal $\mathrm{F}_{1}$ hybrids, where maternal line is Sei- 0 and Col-0, respectively. Data are standardized for abundance of Actin transcript. (c,e) Regions of PAD4 and EDS1 used for ChIP-qPCR assays. (d,f) ChIP-qPCR analyses of promoter fragments (region 1) and exon fragments (region 2) of PAD4 and EDS1 in $\mathrm{F}_{1}$ hybrids and their parents using anti- $\mathrm{H} 3 \mathrm{Ac}$ antibody at $1 \mathrm{dpi}$ with $\mathrm{Pst} \mathrm{DC} 3000$ or $\mathrm{MgCl}_{2}$, and $\mathrm{ChIP}-\mathrm{qPCR}$ analyses of region 1 of PAD4 and EDS1 in $\mathrm{F}_{1}$ hybrids and their parents using anti-H3K27me3 antibody at 1 dpi with Pst DC3000. Error bars indicate s.d.. ${ }^{\star \star} P<0.01$ between infiltrated with Pst DC3000 and $\mathrm{MgCl}_{2}$ of respective samples (Student's $t$-test). ChIP values were normalized to their respective DNA inputs. Data are shown as mean \pm s.d. The results are a representative of three biological repetitions. Error bars indicate s.d.. Data are shown as mean \pm s.d. $(n=3, \mathrm{n}$ means biological replication).

histone modifications of PAD4, EDS1, CBP60g and SARD1 in both hybrids and their parents using chromatin immunoprecipitation (ChIP) followed by quantitative real-time PCR (qRT-PCR). Among the standard histone modifications, acetylation of histone $\mathrm{H} 3(\mathrm{H} 3 \mathrm{Ac})$ is associated with active chromatin and transcription ${ }^{50,51}$, and the trimethylation of $\mathrm{H} 3 \mathrm{~K} 27$ (H3K27me3) is associated with repressed transcription $^{52,53}$. Therefore, we performed ChIP assays using anti-H3Ac and anti-H3K27me3 antibodies against chromatin extracted from leaves infiltrated with Pst $\mathrm{DC} 3000$ or $\mathrm{MgCl}_{2}$ (as a control). The precipitated DNA was purified and analysed by quantitative real-time PCR (qRT-PCR) to assess the chromatin states of the four gene promoters. For PAD4 and EDS1, a region close to the translation initiation codon (ATG) was examined using anti-H3Ac and anti-H3K27me3, and an exon region downstream of the ATG was examined using anti-H3Ac as a control (Fig. 5c,e). As expected, there was a significant increase in $\mathrm{H} 3 \mathrm{Ac}$ at the promoter regions of PAD4 and EDS1 in the reciprocal $F_{1}$ hybrids relative to the parents after infiltration with Pst $\mathrm{DC} 3000$ or $\mathrm{MgCl}_{2}$, and the increase was higher after 
infiltration with Pst DC3000 than with $\mathrm{MgCl}_{2}$ (Fig. 5d,f). There was no significant difference in the level of $\mathrm{H} 3 \mathrm{~K} 27 \mathrm{me} 3$ in these regions between reciprocal $\mathrm{F}_{1}$ hybrids and parents after infiltration with Pst DC3000 (Fig. 5d,f). These results are consistent with the upregulation of these two genes in the $F_{1}$ hybrids (Fig. 5a,b). Similar patterns of $\mathrm{H} 3 \mathrm{Ac}$ and $\mathrm{H} 3 \mathrm{k} 27 \mathrm{me} 3$ were also observed for CBP60g and SARD1 (Supplementary Fig. 6). We performed the same experiment using the Col- $0 \times$ Aa- 0 cross, which had no heterosis for biotrophic bacterial defence, and found that there was no significant increase in $\mathrm{H} 3 \mathrm{Ac}$ at the promoter regions of $P A D 4, E D S 1, S A R D 1$ and $C B P 60 \mathrm{~g}$ in the reciprocal $F_{1}$ hybrids relative to the parents after infiltration with $\mathrm{MgCl}_{2}$ or Pst DC3000, which is consistent with the no significant difference in gene expression between these hybrids and their parents (Supplementary Fig. 7).

Recently, changes in DNA methylation have been correlated with transcription level changes in hybrids, suggesting that DNA methylation plays a role in heterosis for biomass ${ }^{10,11}$. To further investigate whether DNA methylation contributes to the increased pathogen resistance in hybrids, we used bisulphite sequencing to examine the methylation levels of $\mathrm{CG}, \mathrm{CHG}$ and $\mathrm{CHH}$ (where $\mathrm{H}=\mathrm{A}, \mathrm{T}$ or $\mathrm{C}$ ) in the promoters or gene body regions of PAD4, EDS1, ICS1, SARD1 and CBP60g in hybrids and their parental lines after infiltration with Pst $\mathrm{DC} 3000^{54}$. The selected regions were chosen based on a previous whole-genome DNA methylation profiling study in A. thaliana ${ }^{55}$. Degenerate primers flanking these regions were used to amplify bisulphitetreated DNA, and the PCR products were subsequently cloned

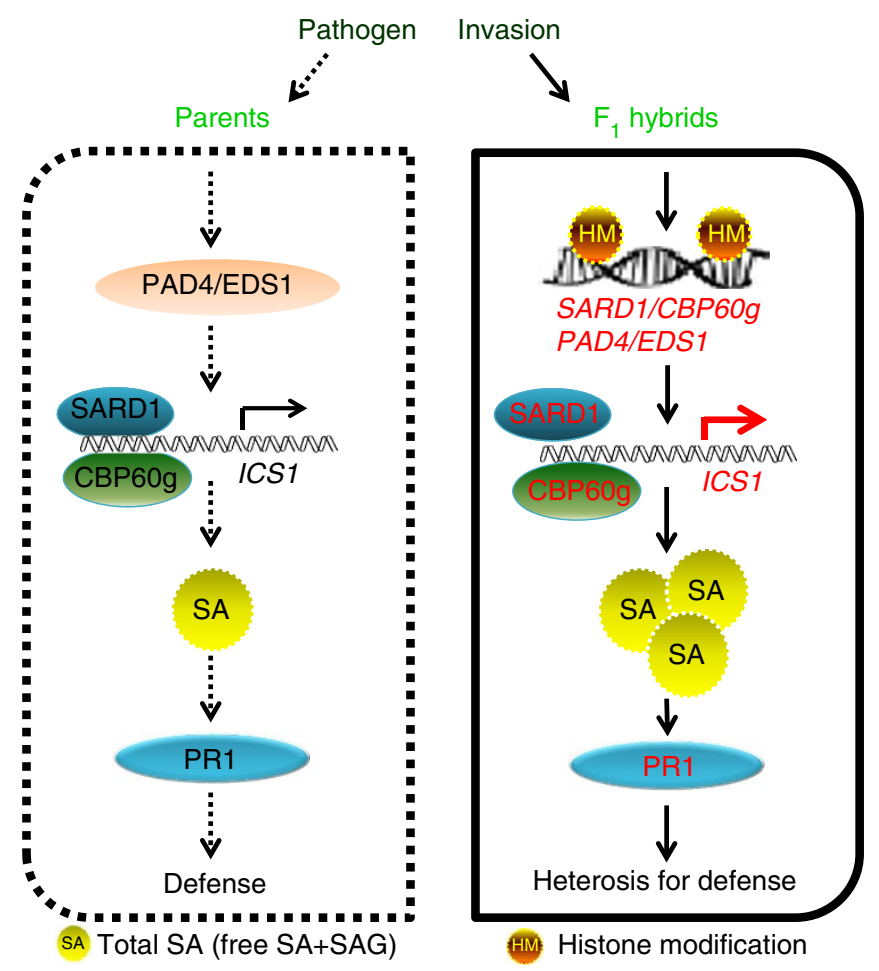

Figure 6 | Working model of enhanced SA biosynthesis in hybrids. SA biosynthesis is activated in Arabidopsis thaliana $\mathrm{F}_{1}$ hybrids and their parents in response to pathogen invasion as a defence strategy, but is not observed in the absence of pathogens. Genes involved in SA biosynthesis were expressed at higher levels in $F_{1}$ hybrids, possibly due to altered histone modifications (such as increased $\mathrm{H} 3 \mathrm{Ac}$ ). As a consequence, higher levels of SA accumulated in the $F_{1}$ hybrids, which we propose plays an important role in the increased resistance of hybrids to biotrophic bacterial pathogens. and sequenced. When methylation levels of $\mathrm{CG}, \mathrm{CHG}$ and $\mathrm{CHH}$ sites were calculated and compared between $\mathrm{F}_{1}$ hybrids and parents, we found that the total methylation levels in the $F_{1}$ hybrids for all tested regions were at mid-parent levels (Supplementary Fig. 10 and Supplementary Data 2), suggesting that DNA methylation may not play a role in heterosis for biotrophic bacterial defence in our tested accessions.

Our data demonstrate that, in response to pathogen invasion, SA biosynthesis was activated, which has not been observed in the absence of pathogens, in both $\mathrm{F}_{1}$ hybrids and their parents as a defence strategy. However, the key genes involved in SA biosynthesis were expressed at higher levels in the $F_{1}$ hybrids than in their parents, possibly through regulation of histone modifications, such as $\mathrm{H} 3$ acetylation. Consequently, higher levels of SA, which plays an important role in resistance to biotrophic bacterial pathogens in $A$. thaliana, are produced in $\mathrm{F}_{1}$ hybrids (Fig. 6).

\section{Discussion}

In this study, we identified certain $F_{1}$ hybrids manifesting significant heterosis (superiority to both parents) for biotrophic bacterial resistance in A. thaliana. We compared genome-wide gene expression profiles of hybrids showing heterosis with those of their parents and found that the expression of key SA biosynthesis genes was significantly upregulated in both reciprocal $\mathrm{F}_{1}$ hybrids compared with either parent (Figs 3 and 5; Supplementary Fig. 6). This indicated that SA accumulation might be increased in hybrids, which was confirmed by direct determination of SA levels in hybrids and parents after bacterial inoculation (Fig. 3). The increased pathogen resistance in hybrids was compromised by pad4, as shown in the $\mathrm{F}_{1}$ hybrids of pad4 (Ler) and pad4 (Col) (Fig. 4), indicating that SA is required for heterosis for biotrophic bacterial defence. Moreover, the upregulated expression of key SA biosynthesis genes was associated with higher levels of $\mathrm{H} 3 \mathrm{Ac}$ in the promoters of these SA-related genes in the $\mathrm{F}_{1}$ hybrids than in the parents (Fig. 5 and Supplementary Fig. 6). As H3 acetylation is associated with active gene expression, this increase suggests that epigenetic regulation of the SA biosynthesis pathway may play an important role in the increased resistance to biotrophic bacterial pathogens in hybrids.

A previous study ${ }^{56}$ showed that $\mathrm{Ws}-0$ is insensitive to the bacterial flagellin flg22, whereas Ws- $0 \times$ Col-0 (flg22 sensitive) exhibited sensitive phenotypes in $\mathrm{F}_{1}$ seedlings. The corresponding dominant locus was further segregated and later found to encode the flagellin receptor FLS2 (refs 57,58). These studies explain why hybrid crosses between Col-0 and Ws in our study did not show heterosis for biotrophic bacterial defence (Supplementary Fig. 1).

On treatment with $S A^{59,60}, \beta$-aminobutyric acid ${ }^{61}$ or various other natural or synthetic compounds ${ }^{62}$, plants acquire enhanced resistance to a broad spectrum of pathogens, a phenomenon called 'inducible defence'. The various induced resistance phenotypes are associated with an enhanced capacity for more rapid and effective activation of cellular defence responses and the expression of various defence-related genes, which were induced only after pathogen attack $59,60,63$. This physiological condition, in which plants are able to better or more rapidly mount defence responses to biotic or abiotic stress, is called the 'primed state' 64 . As revealed in our study, the key genes involved in the SA biosynthesis pathway (PAD4, EDS1, SARD1, CBP60g and ICS1) were all significantly upregulated in $F_{1}$ hybrids relative to their parents after inoculation with the pathogen (Figs 3 and 5; Supplementary Fig. 6), eventually leading to increased SA accumulation in hybrids (Fig. 3c). Moreover, the expression peak for all of these genes was $8 \mathrm{~h}$ earlier in hybrids than in their parents, and this faster activation was only induced under 
pathogen invasion (Figs 3 and 5; Supplementary Fig. 6). These observations indicate that $\mathrm{F}_{1}$ hybrids responded more efficiently to pathogen attack than did their parents by expressing SA pathway genes more quickly and at higher levels. Therefore, $\mathrm{F}_{1}$ hybrids showed a primed state under pathogen attack, which might be an important step towards heterosis for biotrophic bacterial defence in A. thaliana.

The mechanistic basis of gene priming is poorly understood until now. Histone modifications such as H3K4 trimethylation and $\mathrm{H} 3$ acetylation are systemically set following treatment with the SA analogue benzothiadiazole ${ }^{65}$. However, the primed genes were not activated or were activated to a limited extent, even with altered histone modifications. Instead, these changes in histone modifications may serve as a memory of the primary treatment, which is then associated with an amplified reaction to the following stress (water infiltration) ${ }^{65}$. In our study, $\mathrm{H} 3$ acetylation levels in the promoter regions of the key SA biosynthesis genes were higher in $\mathrm{F}_{1}$ hybrids than in their parents (Fig. 5; Supplementary Fig. 6) even after mock (10 $\left.\mathrm{mM} \mathrm{MgCl}_{2}\right)$ treatment, and this difference increased further after inoculation with bacterial pathogen. Moreover, the higher level of histone modifications in the $\mathrm{F}_{1}$ hybrids under $\mathrm{MgCl}_{2}$ inoculation did not induce expression of these genes (Fig. 5; Supplementary Fig. 6), an observation reminiscent of the findings reported in the abovementioned study ${ }^{65}$. Accordingly, we speculate that hybridization might induce a primed state characterized by enhanced histone acetylation in the promoter regions of these SA biosynthesis genes, which then enables a more rapid and stronger activation of defence-related genes on pathogen invasion.

A previous study ${ }^{66}$ showed that promoter insertion/deletion (INDEL) polymorphisms were highly correlated with differential gene expression between rice hybrids and their parents, which might contribute to the biomass heterosis. Therefore, we also sequenced the $2-\mathrm{kb}$ regions upstream of the ATG codons of the key SA biosynthesis genes in different $A$. thaliana ecotypes. Surprisingly, we found an identical 612-bp INDEL in the promoter of CBP60g in nine ecotypes (Aa-0, No-0, Nd-0, Est-0, $\mathrm{C} 24$, Co-1, Gr-1, Ha-0, Dr-0), and none of the $\mathrm{F}_{1}$ crosses of Col- 0 with these nine ecotypes showed increased resistance to the biotrophic bacterial pathogen. The specific relationship between this INDEL and the differential expression level of genes in hybrids and parents remains to be explored. It has been proposed $^{20}$ that heterosis for biomass and for freezing tolerance were not genetically related in A. thaliana. In this study, our data suggest that there was no direct relationship between heterosis for biomass and for biotrophic bacterial resistance. The $\mathrm{F}_{1}$ hybrids from two combinations (Col-0 \& C24 and Ler \& Col-0), which exhibit heterosis for biomass ${ }^{11,14}$, show no heterosis for biotrophic bacteria defence in our study (Supplementary Fig. 11). The $F_{1}$ hybrids from two other combinations (Col-0 \& Sei-0 and Col-0 \& Ler) exhibit heterosis for biotrophic bacteria defence, but show no (crosses between Col-0 and Sei-0) or only weak (crosses between Col-0 and Ler) heterosis for biomass (Supplementary Table 4). Taken together, these studies suggest that different molecular mechanisms account for different heterotic traits.

\footnotetext{
Methods

Plant materials. The A. thaliana accessions Aa-0 (N934), Est-0 (N1148) and Sei-0 (N1504) were obtained from the Nottingham A. thaliana Stock Centre. All other accessions, WS-2 (CS76631), Ler-1 (CS6928), C24 (CS28127), Co-1 (CS76468), Gr-1 (CS76496), Ha-0 (CS76500), Dr-0 (CS76475), Kil-0 (CS76526), Kro-0 (CS76533), Bch-1 (CS76444), Db-1 (CS76471), Hs-0 (CS76515), An-1 (CS76435), La-0 (CS76538), Lip-0 (CS76542), No-0 (CS24239) and Nd-0 (CS6803), were obtained from the $A$. thaliana Biological Resource Center. Crosses were performed by dissecting immature flowers before anther dehiscence and applying pollen to the exposed pistils. $F_{1}$ hybrid lines were generated by crossing the indicated parental
}

lines. $\mathrm{F}_{1}$ hybrids of pad4 mutants were generated by crossing a T-DNA insertion line in the Col-0 background (SALK_089936) with pad4-2 in the Ler background ${ }^{38}$.

Growth conditions. Plants were grown on Murashige and Skoog plates containing $1 \%$ sucrose at $23^{\circ} \mathrm{C}$ under white light conditions $\left(100 \mu \mathrm{mol} \mathrm{m}^{-2} \mathrm{~s}^{-1} ; 16-\mathrm{h} \mathrm{light} / 8\right.$-h dark). Plants for pathogen inoculation were grown under short-day conditions (8-h light) and leaves from 4 -week-old plants were used. For other assays, 6-week-old plants grown at $16^{\circ} \mathrm{C}$ under long-day conditions (16-h light) were used. All plants were grown at the controlled temperature $\left(16^{\circ}\right.$ or $\left.23^{\circ} \pm 0.1^{\circ} \mathrm{C}\right)$ with $65 \%$ relative humidity. Chambers were illuminated using a 1:1 mix of Cool White and Gro-lux wide-spectrum fluorescent lights with a fluence rate of $125-175 \mu \mathrm{mol} \mathrm{m}^{-2} \mathrm{~s}^{-1}$.

RNA extraction and qRT-PCR. Leaves from 4-week-old plants were infiltrated with Pst DC3000 $\left(1 \times 10^{5}\right.$ c.f.u. $\left.\mathrm{ml}^{-1}\right)$ or with $10 \mathrm{mM} \mathrm{MgCl}_{2}$ (mock) and collected at different time points. At least five leaves from different plants were pooled in each sample for qRT-PCR. Leaves were ground to a powder in liquid nitrogen, and total RNA was extracted using the RNeasy Plant Mini kit (Qiagen) with an OnColumn DNase I digestion treatment. Spectrophotometric and gel electrophoretic analyses were performed to detect RNA quality. To synthesize cDNA, $1 \mu \mathrm{g}$ of RNA was used in the SuperScript III First-Strand Synthesis System (Invitrogen). Realtime qPCR analysis was performed using Power SYBR Green PCR Master Mix (Applied Biosystems) on a Bio-Rad CFX96 real-time PCR detection system. Each experiment was repeated with three independent samples, and qRT-PCR reactions were performed in three technical replicates for each sample. All primers used are listed in Supplementary Table 5.

mRNA-seq and data analysis. At least 30 leaves from different 4 -week-old plants infiltrated with Pst DC3000 $\left(1 \times 10^{5}\right.$ c.f.u. $\left.\mathrm{ml}^{-1}\right)$ were collected at 1,2 and 3 days after infiltration. Total RNA was extracted as described above and was treated with RNase-free DNase I (New England Biolabs) to remove any contaminating genomic DNA. Total RNA (1-10 $\mu \mathrm{g})$ was used for the construction of each mRNA-seq library. mRNA was extracted from total RNA using Dynabeads oligo(dT) (Invitrogen Dynal) following the manufacturer's directions. First- and second-strand cDNA were generated using Superscript II reverse transcriptase (Invitrogen) and random hexamer primers. Double-stranded cDNA was fragmented by nebulization and used for mRNA library construction following the standard Illumina protocol. Barcodes were added to each mRNA-seq library, and all libraries were sequenced using the HiSeq 2000 sequencing system according to the manufacture's instruction (Illumina). TopHat and Cufflink software packages were used for the mRNAseq data analysis to identify DEGs. The BiNGO plugin of Cytoscape software was used for GO analysis. SAS software was used for significant difference analysis.

After sequencing adapters and low-quality reads were removed, sequencing reads were mapped to the TAIR 10 A. thaliana reference genome by TopHat (http://tophat.cbcb.umd.edu/) using default parameters. The TopHat results were exported into Cufflink software so that the sequencing reads could be assembled into known transcripts based on the A. thaliana gene model annotation of TAIR10. The abundance of assembled transcripts was also calculated in fragments per kilobase of exon model per million mapped fragments (FPKM). Following Cufflink, Cuffmerge software was used to merge the assembled transcripts from each sample into one file using default parameters. Finally, transcript abundance profiling was undertaken by Cuffdiff software using a Poisson fragment distribution and a false discovery rate (FDR) $<0.05$ as the two default parameters Cufflink, Cuffmerge and Cuffdiff are from the Cufflink software package (http://cufflinks.cbcb.umd.edu).

To classify genes into expression patterns, non-additive expression levels in hybrids were identified by comparing the expression in hybrids with the mid-parent values; genes with $P<0.05$ (Student's $t$-test) were considered to be non-additively expressed, and genes with $P>0.05$ (Student's $t$-test) were considered to be additively expressed. Similarly, for genes that were differentially expressed in the parents, if expression in the hybrids was significantly different from the high parent but not from the low parent, then they were classified as low parent expression'; if expression in the hybrids was significantly different from the low parent but not from the high parent, then they were classified as 'high parent expression'.

GO results were extracted from the TAIR10 gene annotation, and a functional enrichment analysis was performed using the BiNGO plugin of Cytoscape (http://www.psb.ugent.be/cbd/papers/BiNGO/Home.html). Pearson productmoment correlation coefficients were calculated using $\mathrm{R}$ software.

Bacterial inoculation and determination of bacterial growth. Pst DC3000 was grown at $28^{\circ} \mathrm{C}$ in King's B medium $\left(10 \mathrm{mg} \mathrm{ml}^{-1}\right.$ protease peptone, $1.5 \mathrm{mg} \mathrm{ml}^{-1}$ $\mathrm{K}_{2} \mathrm{HPO}_{4}, 15 \mathrm{mg} \mathrm{ml}^{-1}$ glycerol) ${ }^{67}$ supplemented with $25 \mu \mathrm{g} \mathrm{ml}{ }^{-1}$ rifampicin. Mature, fully expanded leaves of 4-week-old plants were infected with suspensions of bacterial cells in $10 \mathrm{mM} \mathrm{MgCl}$ by pressing a 1-ml syringe (without a needle) against the abaxial side of the leaves and forcing the suspension through the stomata into the intercellular spaces. The bacterial dose was $1 \times 10^{5}$ c.f.u. $\mathrm{cm}^{-2}$ leaf area (equivalent to $\mathrm{OD}_{600}=0.0002$ ).

Five days after inoculation, the degree of bacterial growth in plant leaves was determined by harvesting 16-24 infected leaves per sample (approximately 
eight plants), and a $0.28-\mathrm{cm}^{2}$ leaf disk was cut from each leaf with a no. 2 cork borer. Disks were put into a microcentrifuge tube containing $1 \mathrm{ml}$ of $10 \mathrm{mM}$ $\mathrm{MgCl}_{2}$ and ground with a plastic pestle. This material was diluted, and $60-\mu \mathrm{l}$ samples were spread on King's B plates containing $25 \mu \mathrm{g} \mathrm{ml}^{-1}$ rifampicin. Plates were incubated for 2 days at $28^{\circ} \mathrm{C}$. Eight replicate samples per genotype were assayed to obtain means and s.d., which were determined from the logarithm of the number of c.f.u. $\mathrm{cm}^{-2}$.

Determination of endogenous levels of SA and SAG. Mature leaves of 4-weekold plants were infected with Pst DC3000 at a dose of $1 \times 10^{5}$ c.f.u. $\mathrm{cm}^{-2}$ leaf area (equivalent to $\mathrm{OD}_{600}=0.0002$ ) or mock infected with $10 \mathrm{mM} \mathrm{MgCl}_{2}$. At $1 \mathrm{dpi}$, samples were collected (at least $0.2 \mathrm{~g}$ tissue per sample, from approximately eight plants) and frozen in liquid nitrogen. SA and SAG were extracted and quantified from $\sim 200 \mathrm{mg}$ of tissue per sample using high-performance liquid chromatography analysis on an ARH-601 organic acids column $(100 \mathrm{~mm} \times 6.5 \mathrm{~mm}$; Transgenomic Inc., Omaha, NE, USA) run at $55^{\circ} \mathrm{C}$ in $0.01 \mathrm{~N} \mathrm{H}_{2} \mathrm{SO}_{4}$ with a flow rate of $0.6 \mathrm{ml} \mathrm{min}^{-1}$. Three replicates were taken for each data point. Statistical analyses were performed using Student's $t$-test of the differences between the two means.

ChIP. About $2 \mathrm{~g}$ materials were cross-linked with $1 \%$ formaldehyde in a vacuum for $35 \mathrm{~min}$, and were then ground to powder in liquid nitrogen. The chromatin complexes were isolated and sonicated, and were then incubated with anti-acetylHistone $\mathrm{H} 3$ antibody and anti-trimethyl-Histone H3 (Lys27) antibody. $10 \mu \mathrm{g}$ of anti-AcH3 (Upstate; 06-599) and anti-H3K27me3 (Millipore; 07-449) antibodies $^{49,68}$ were used in a $10-\mu 1$ volume for immunoprecipitation. An equal amount of sample without antibody was used as a mock control. The precipitated DNA was recovered and analysed by qPCR with Power SYBR Green PCR Master Mix (Applied Biosystems) using specific primers listed in Supplementary Table 5. Each ChIP value was normalized to its respective input DNA value. All ChIPqPCR experiments were independently performed in triplicate.

Genomic DNA extraction and bisulphite sequencing. Four-week-old plants were grown under short-day conditions and infiltrated with Pst DC3000. Leaves were collected at $1 \mathrm{dpi}$ and genomic DNA was extracted using the DNeasy Plant Mini kit (Qiagen). Then, $\sim 500 \mathrm{ng}$ genomic DNA was used for bisulphite conversion with the EZ DNA Methylation-Gold kit (ZYMO Research) according to the manufacturer's instructions. Bisulphite-treated DNA $(1 \mu \mathrm{l})$ was then amplified by PCR in a $25-\mu l$ reaction using ZymoTaq DNA polymerase (ZYMO Research) and degenerate primers (Supplementary Table 5). PCR products were resolved on a $1 \%$ agarose gel, and then excised, purified and cloned into a pGEM-T vector (Promega) for sequencing. For each plant genotype, 20 independent top-strand clones were sequenced. For tested regions, bisulphite DNA sequences were analysed, and the levels of DNA methylation were calculated using the online Kismeth program ${ }^{54}$. For each genotype, the percentage of cytosine methylation in each context (CG, $\mathrm{CHG}$ or $\mathrm{CHH}$ ) was calculated.

Trypan blue staining. Leaves were immersed in $5 \mathrm{ml}$ lactophenol trypan blue solution $\left(250 \mu \mathrm{g} \mathrm{ml}^{-1}\right.$ trypan blue, $25 \%$ (w/v) lactic acid, $25 \%$ water-saturated phenol, $25 \%$ glycerol, $\mathrm{H}_{2} \mathrm{O}$ ), slow-release vacuum-infiltrated for $5 \mathrm{~min}$, and then reinfiltrated for an additional $5 \mathrm{~min}$. Samples were then heated over boiling water for $2 \mathrm{~min}$ and cooled before replacement of the lactophenol trypan blue solution with a chloral hydrate solution $\left(25 \mathrm{~g}\right.$ in $\left.10 \mathrm{ml} \mathrm{H}_{2} \mathrm{O}\right)$ for destaining. After multiple exchanges of chloral hydrate solution, samples were equilibrated for several hours in $70 \%$ glycerol. For examination, leaves were mounted adaxial side up and examined using a microscope.

\section{References}

1. Chen, Z. J. Genomic and epigenetic insights into the molecular bases of heterosis. Nature reviews. Genetics 14, 471-482 (2013).

2. Birchler, J. A., Yao, H., Chudalayandi, S., Vaiman, D. \& Veitia, R. A. Heterosis. Plant Cell 22, 2105-2112 (2010).

3. Lippman, Z. B. \& Zamir, D. Heterosis: revisiting the magic. Trends Genet. 23, 60-66 (2007)

4. Schnable, P. S. \& Springer, N. M. Progress toward understanding heterosis in crop plants. Annu. Rev. Plant Biol. 64, 71-88 (2013).

5. Hochholdinger, F. \& Hoecker, N. Towards the molecular basis of heterosis. Trends Plant Sci. 12, 427-432 (2007).

6. Birchler, J. A., Auger, D. L. \& Riddle, N. C. In search of the molecular basis of heterosis. Plant Cell 15, 2236-2239 (2003).

7. Hua, J. et al. Single-locus heterotic effects and dominance by dominance interactions can adequately explain the genetic basis of heterosis in an elite rice hybrid. Proc. Natl Acad. Sci. USA 100, 2574-2579 (2003).

8. Ni, Z. et al. Altered circadian rhythms regulate growth vigour in hybrids and allopolyploids. Nature 457, 327-331 (2009).

9. Krieger, U., Lippman, Z. B. \& Zamir, D. The flowering gene SINGLE FLOWER TRUSS drives heterosis for yield in tomato. Nat. Genet. 42, 459-463 (2010).
10. Groszmann, M. et al. Changes in 24-nt siRNA levels in Arabidopsis hybrids suggest an epigenetic contribution to hybrid vigor. Proc. Natl Acad. Sci. USA 108, 2617-2622 (2011).

11. Shen, H. et al. Genome-wide analysis of DNA methylation and gene expression changes in two Arabidopsis ecotypes and their reciprocal hybrids. Plant Cell 24, 875-892 (2012).

12. Abbott, R. J. \& Gomes, M. F. Population genetic structure and outcrossing rate of Arabidopsis thaliana (L.) Heynh. Heredity 62, 411-418 (1989).

13. Barth, S., Busimi, A., Utz, H. F. \& Melchinger, A. Heterosis for biomass yield and related traits in five hybrids of Arabidopsis thaliana L. Heynh. Heredity 91 , 36-42 (2003)

14. Meyer, R. C., Torjek, O., Becher, M. \& Altmann, T. Heterosis of biomass production in Arabidopsis. Establishment during early development. Plant Physiol. 134, 1813-1823 (2004).

15. Sharma, R., Griffing, B. \& Scholl, R. Variations among races of Arabidopsis thaliana (L.) Heynh for survival in limited carbon dioxide. Theor. Appl. Genet. 54, 11-15 (1979).

16. Mitchell-Olds, T. Interval mapping of viability loci causing heterosis in Arabidopsis. Genetics 140, 1105-1109 (1995).

17. Alonso-Blanco, C., Blankestijn-de Vries, H., Hanhart, C. J. \& Koornneef, M. Natural allelic variation at seed size loci in relation to other life history traits of Arabidopsis thaliana. Proc. Natl Acad. Sci. USA 96, 4710-4717 (1999).

18. Narang, R. A. \& Altmann, T. Phosphate acquisition heterosis in Arabidopsis thaliana: a morphological and physiological analysis. Plant and Soil 234, 91-97 (2001).

19. Rohde, P., Hincha, D. K. \& Heyer, A. G. Heterosis in the freezing tolerance of crosses between two Arabidopsis thaliana accessions (Columbia-0 and C24) that show differences in non-acclimated and acclimated freezing tolerance. Plant J. 38, 790-799 (2004).

20. Korn, M., Peterek, S., Mock, H. P., Heyer, A. G. \& Hincha, D. K. Heterosis in the freezing tolerance, and sugar and flavonoid contents of crosses between Arabidopsis thaliana accessions of widely varying freezing tolerance. Plant Cell Environ. 31, 813-827 (2008).

21. Todesco, M. et al. Activation of the Arabidopsis thaliana immune system by combinations of common ACD6 alleles. PLoS Genet. 10, e1004459 (2014).

22. Bomblies, K. et al. Autoimmune response as a mechanism for a DobzhanskyMuller-type incompatibility syndrome in plants. PLoS Biol. 5, e236 (2007).

23. Agrios, G. N. Plant Pathology. Fourth Edition. New York: ACADEMIC PRESS INC, (1997).

24. Chisholm, S. T., Coaker, G., Day, B. \& Staskawicz, B. J. Host-microbe interactions: shaping the evolution of the plant immune response. Cell 124, 803-814 (2006).

25. Dodds, P. N. \& Rathjen, J. P. Plant immunity: towards an integrated view of plant-pathogen interactions. Nat. Rev. Genet. 11, 539-548 (2010).

26. Malamy, J., Carr, J. P., Klessig, D. F. \& Raskin, I. Salicylic Acid: a likely endogenous signal in the resistance response of tobacco to viral infection. Science 250, 1002-1004 (1990).

27. Yalpani, N., Silverman, P., Wilson, T. M., Kleier, D. A. \& Raskin, I. Salicylic acid is a systemic signal and an inducer of pathogenesis-related proteins in virus-infected tobacco. Plant Cell 3, 809-818 (1991).

28. Vlot, A. C., Dempsey, D. A. \& Klessig, D. F. Salicylic Acid, a multifaceted hormone to combat disease. Annu. Rev. Phytopathol. 47, 177-206 (2009).

29. Durrant, W. \& Dong, X. Systemic acquired resistance. Annu. Rev. Phytopathol. 42, 185-209 (2004)

30. Cao, H., Bowling, S. A., Gordon, A. S. \& Dong, X. Characterization of an Arabidopsis mutant that is nonresponsive to inducers of systemic acquired resistance. Plant Cell 6, 1583-1592 (1994).

31. Dempsey, D. A., Vlot, A. C., Wildermuth, M. C. \& Klessig, D. F. Salicylic Acid biosynthesis and metabolism. Arabidopsis Book 9, e0156 (2011).

32. Wildermuth, M. C., Dewdney, J., Wu, G. \& Ausubel, F. M. Isochorismate synthase is required to synthesize salicylic acid for plant defence. Nature 414, 562-565 (2001).

33. Zhou, N., Tootle, T. L., Tsui, F., Klessig, D. F. \& Glazebrook, J. PAD4 functions upstream from salicylic acid to control defense responses in Arabidopsis. Plant Cell 10, 1021-1030 (1998).

34. Zhang, Y. et al. Control of salicylic acid synthesis and systemic acquired resistance by two members of a plant-specific family of transcription factors. Proc. Natl Acad. Sci. USA 107, 18220-18225 (2010).

35. Serrano, M. et al. Export of salicylic acid from the chloroplast requires the multidrug and toxin extrusion-like transporter EDS5. Plant Physiol. 162, 1815-1821 (2013).

36. Nawrath, C. \& Métraux, J.-P. Salicylic acid induction-deficient mutants of Arabidopsis express $P R-2$ and $P R-5$ and accumulate high levels of camalexin after pathogen inoculation. Plant Cell 11, 1393-1404 (1999).

37. Nawrath, C., Heck, S., Parinthawong, N. \& Métraux, J.-P. EDS5, an essential component of salicylic acid-dependent signaling for disease resistance in 
Arabidopsis, is a member of the MATE transporter family. Plant Cell 14, 275-286 (2002).

38. Feys, B. J., Moisan, L. J., Newman, M. A. \& Parker, J. E. Direct interaction between the Arabidopsis disease resistance signaling proteins, EDS1 and PAD4. EMBO J. 20, 5400-5411 (2001).

39. Falk, A. et al. EDS1, an essential component of R gene-mediated disease resistance in Arabidopsis has homology to eukaryotic lipases. Proc. Natl Acad. Sci. USA 96, 3292-3297 (1999).

40. Zhang, Y. et al. Control of salicylic acid synthesis and systemic acquired resistance by two members of a plant-specific family of transcription factors. Proc. Natl Acad. Sci. USA 107, 18220-18225 (2010).

41. Muralidharan, S. et al. Different mechanisms for Arabidopsis thaliana hybrid necrosis cases inferred from temperature responses. Plant Biol. (Stuttg) 16, 1033-1041 (2014).

42. Alcazar, R., Garcia, A. V., Parker, J. E. \& Reymond, M. Incremental steps toward incompatibility revealed by Arabidopsis epistatic interactions modulating salicylic acid pathway activation. Proc. Natl Acad. Sci. USA 106, 334-339 (2009).

43. Ward, E. R. et al. Coordinate gene activity in response to agents that induce systemic acquired resistance. Plant Cell 3, 1085-1094 (1991).

44. Jirage, D. et al. Arabidopsis thaliana PAD4 encodes a lipase-like gene that is important for salicylic acid signaling. Proc. Natl Acad. Sci. USA 96, 13583-13588 (1999).

45. Glazebrook, J., Rogers, E. E. \& Ausubel, F. M. Use of Arabidopsis for genetic dissection of plant defence responses. Annu. Rev. Genet. 31, 547-569 (1997).

46. Glazebrook, J., Rogers, E. E. \& Ausubel, F. M. Isolation of Arabidopsis mutants with enhanced disease susceptibility by direct screening. Genetics 143, 973-982 (1996).

47. He, G. et al. Global epigenetic and transcriptional trends among two rice subspecies and their reciprocal hybrids. Plant Cell 22, 17-33 (2010).

48. Jaskiewicz, M., Conrath, U. \& Peterhansel, C. Chromatin modification acts as a memory for systemic acquired resistance in the plant stress response. $E M B O$ Rep. 12, 50-55 (2011)

49. Mosher, R. A., Durrant, W. E., Wang, D., Song, J. \& Dong, X. A comprehensive structure-function analysis of Arabidopsis SNI1 defines essential regions and transcriptional repressor activity. Plant Cell 18, 1750-1765 (2006).

50. Zhang, Y. \& Reinberg, D. Transcription regulation by histone methylation: interplay between different covalent modifications of the core histone tails. Genes Dev. 15, 2343-2360 (2001).

51. Strahl, B. D. \& Allis, C. D. The language of covalent histone modifications. Nature 403, 41-45 (2000).

52. Zhang, X. et al. Whole-genome analysis of histone H3 lysine 27 trimethylation in Arabidopsis. PLoS Biol. 5, el29 (2007).

53. Charron, J. B., He, H., Elling, A. A. \& Deng, X. W. Dynamic landscapes of four histone modifications during deetiolation in Arabidopsis. Plant Cell 21, 3732-3748 (2009).

54. Gruntman, E. et al. Kismeth: analyzer of plant methylation states through bisulfite sequencing. BMC Bioinformatics 9, 371 (2008).

55. Schmitz, R. J. et al. Patterns of population epigenomic diversity. Nature 495, 193-198 (2013).

56. Gómez-Gómez, L., Felix, G. \& Boller, T. A single locus determines sensitivity to bacterial flagellin in Arabidopsis thaliana. Plant J. 18, 277-284 (1999).

57. Gomez-Gomez, L. \& Boller, T. FLS2: an LRR receptor-like kinase involved in the perception of the bacterial elicitor flagellin in Arabidopsis. Mol. Cell 5, 1003-1011 (2000).

58. Zipfel, C. et al. Bacterial disease resistance in Arabidopsis through flagellin perception. Nature 428, 764-767 (2004).

59. Sticher, L., Mauch-Mani, B. \& Métraux, J. P. Systemic acquired resistance. Annu. Rev. Phytopathol. 35, 235-270 (1997).

60. Ryals, J. A. et al. Systemic acquired resistance. Plant Cell 8, 1809 (1996).

61. Jakab, G. et al. $\beta$-Aminobutyric acid-induced resistance in plants. Eur. J. Plant Pathol. 107, 29-37 (2001).
62. Kuć, J. Concepts and direction of induced systemic resistance in plants and its application. Eur. J. Plant Pathol. 107, 7-12 (2001).

63. Conrath, U., Pieterse, C. M. \& Mauch-Mani, B. Priming in plant-pathogen interactions. Trends Plant Sci. 7, 210-216 (2002).

64. Conrath, U. et al. Priming: getting ready for battle. Mol. Plant Microbe Interact. 19, 1062-1071 (2006).

65. Jaskiewicz, M., Conrath, U. \& Peterhänsel, C. Chromatin modification acts as a memory for systemic acquired resistance in the plant stress response. $E M B O$ Rep. 12, 50-55 (2011).

66. Zhang, H.-Y. et al. A genome-wide transcription analysis reveals a close correlation of promoter INDEL polymorphism and heterotic gene expression in rice hybrids. Mol. Plant 1, 720-731 (2008).

67. King, E. O., Ward, M. K. \& Raney, D. E. Two simple media for the demonstration of pyocyanin and fluorescin. J. Lab. Clin. Med. 44, 301-307 (1954).

68. Jang, I. C., Chung, P. J., Hemmes, H., Jung, C. \& Chua, N. H. Rapid and reversible light-mediated chromatin modifications of Arabidopsis phytochrome A locus. Plant Cell 23, 459-470 (2011).

\section{Acknowledgements}

We thank Dr Jane E. Parker for the pad4-2, pad4-5, eds1-2 and eds1-1 mutants; Dr Jane Glazebrook for the pad4-1, sard1, cbp60g and cbp60g sard1 mutants; Dr Shunping Yan for suggestions about the project; and Dr Mian Zhou for assistance with SA measurements. This work was supported by the National Basic Research Program of China (973 Program: 2012CB910900; 2012CB114006), the National Natural Science Foundation (31330048), the Ministry of Agriculture of China (948 Program: 2011-G2B), the Agriculture and Food Research Initiative competitive grant (2011-67013-30125) of the USDA National Institute of Food and Agriculture and the Peking-Tsinghua Center for Life Sciences. This work was also supported in part by grants from the National Institutes of Health (2R01-GM069594-09) and by the Howard Hughes Medical Institute and the Gordon and Betty Moore Foundation (grant GBMF3032) to X.D. L.Y. was a Monsanto Fellow during her visit to Yale University.

\section{Author contributions}

L.Y., G.H., C.A. and X.W.D. designed the experiments. X.Y.Z. and X.D. measured the endogenous levels of SA and SAG, and L.Y. performed all other experiments. M.Y. helped with the $\mathrm{F}_{1}$ hybrid crossing. L.Y., G.H., J.L. and X.W.D. analysed the experimental data and B.L. analysed the mRNA-seq data. L.Y., G.H., J.L., B.L. and X.W.D. wrote the manuscript.

\section{Additional information}

Accession codes: All original data sets have been deposited in the Gene Expression Omnibus database under accession number GSE62256.

Supplementary Information accompanies this paper at http://www.nature.com/ naturecommunications

Competing financial interests: The authors declare no competing financial interests.

Reprints and permission information is available online at http://npg.nature.com/ reprintsandpermissions/

How to cite this article: Yang, L. et al. Salicylic acid biosynthesis is enhanced and contributes to increased biotrophic pathogen resistance in Arabidopsis hybrids. Nat. Commun. 6:7309 doi: 10.1038/ncomms8309 (2015).

This work is licensed under a Creative Commons Attribution 4.0 International License. The images or other third party material in this article are included in the article's Creative Commons license, unless indicated otherwise in the credit line; if the material is not included under the Creative Commons license, users will need to obtain permission from the license holder to reproduce the material. To view a copy of this license, visit http://creativecommons.org/licenses/by/4.0/ 


\section{Corrigendum: Salicylic acid biosynthesis is enhanced and contributes to increased biotrophic pathogen resistance in Arabidopsis hybrids}

Li Yang, Bosheng Li, Xiao-yu Zheng, Jigang Li, Mei Yang, Xinnian Dong, Guangming He, Chengcai An \& Xing Wang Deng

Nature Communications 6:7309 doi: 10.1038/ncomms8309 (2015); Published online 12 Jun 2015; Updated 12 Aug 2015

In the last paragraph of the Discussion section in this Article, the hybrid Ler \& C24 was incorrectly referred to as Ler \& Col-0. The following is the correct sentence: 'The F1 hybrids from two combinations (Col-0 \& C24 and Ler \& C24), which exhibit heterosis for biomass $^{11,14}$, show no heterosis for biotrophic bacteria defence in our study (Supplementary Fig. 11)'. 